\title{
ARTICLE OPEN \\ Prevalence of inappropriate prescribing of inhaled corticosteroids for respiratory tract infections in the Netherlands: a retrospective cohort study
}

\author{
Martina Teichert ${ }^{1,2}$, Tjard Schermer ${ }^{3}$, Lotte van den Nieuwenhof ${ }^{3}$, Peter AGM De Smet ${ }^{1,4}$ and Michel Wensing $^{1}$
}

BACKGROUND: Inhaled corticosteroids (ICS) are recommended in prevailing guidelines for use in patients with persistent asthma or moderate-to-severe chronic obstructive pulmonary disease (COPD) and recurrent exacerbations. Recent data from Australia showed that $44 \%$ of patients with a single ICS dispensing and without other respiratory inhalation medications ('one-off ICS') were co-dispensed oral antibiotics. Evidence of the merit of ICS for treating respiratory infections in subjects without asthma or COPD is lacking.

AIMS: The aims of the study were to describe the rate of one-off ICS dispensing in combination with oral antibiotics in subjects without chronic respiratory conditions in the Netherlands, and to compare this with the rate of one-off ICS dispensing in combination with oral antibiotics as reported earlier from Australia.

METHODS: Dispensing data were obtained from the Dutch Foundation of Pharmaceutical Statistics. Additional information was available on patients' age, sex and prescriber. Patients with any ICS dispensing in 2011 were selected.

RESULTS: Data were available from 1,725 Dutch community pharmacies (88\%). Of 845,068 ICS users in 2011 , 10\% were dispensed one-off ICS, among which $13 \%$ had oral antibiotics co-dispensed. These ICS were mainly prescribed by general practitioners, mostly during winter months, for elderly persons, after high dosages of oral corticosteroids, and in single-inhaler combinations with a long-acting $\beta_{2}$-agonist. The extrapolated total annual expense for this ICS use was $€ 555,000$.

CONCLUSION: In the Netherlands one-off ICS dispensing in combination with oral antibiotics in subjects without chronic respiratory conditions was considerably lower than in Australia.

npj Primary Care Respiratory Medicine (2014) 24, 14086; doi:10.1038/npjpcrm.2014.86; published online 16 October 2014

\section{INTRODUCTION}

Inhaled corticosteroids (ICS) have pronounced anti-inflammatory properties. ${ }^{1}$ They are therefore effective in reducing morbidity and mortality in patients with persistent asthma ${ }^{2-4}$ and in diminishing the incidence of exacerbations in patients with chronic obstructive pulmonary disease (COPD).$^{5-7}$ Besides these benefits, ICS use can cause adverse effects like oropharyngeal candidiasis, easy bruisability, cataract, open-angle glaucoma and lowering of spine and femur bone densities. ${ }^{6,7}$ Furthermore, ICS use is associated with an increased risk of pneumonia, possibly due to protracted symptomatic exacerbations. ${ }^{8,9}$

In the prevailing guidelines for asthma and COPD, the evidence of the effectiveness of ICS use has been weighted critically, and for their use outside these recommendations the risk of side effects does not outweigh the benefits. ${ }^{10-13}$ In national and international guidelines for asthma, ICS are recommended as preventive medication for daily use to improve disease control in addition to bronchodilators. ${ }^{10-14}$ Pharmacotherapy for patients with COPD is mainly based on bronchodilators, and ICS are only advised in patients with moderate-to-very severe COPD with a high risk of exacerbations. ${ }^{11,13}$

In the Netherlands the use of inhalation medication increased by $7 \%$ from 2007 to $2012 .^{15}$ In 2012, the combination of salmeterol and fluticasone ranked first on the list of annual costs of reimbursed drugs ( $€ 118$ million), and the combination of formoterol with budesonide was ranked third ( $€ 94$ million). ${ }^{16}$ It is, however, questionable whether all ICS prescribing is consistent with the prevailing guidelines. Inappropriate prescribing practices have previously been reported: a Dutch study concluded from a questionnaire administered to general practitioners (GPs) that $30 \%$ of asthma and/or COPD patients who used ICS did not have a clear indication for this treatment. ${ }^{17}$ In a study from the United Kingdom it was seen that $25 \%$ of COPD patients received ICS, which was not consistent with the recently published GOLD guidelines. ${ }^{18}$ Another study from the United Kingdom found $43 \%$ overtreatment with ICS in COPD patients, ${ }^{1}$ and a Spanish study reported inappropriate ICS use in 18\% of COPD patients. ${ }^{19}$ A recent Australian study showed that $44 \%$ of patients with a single ICS dispensing and without other respiratory inhalation medication were co-dispensed oral antibiotics, indicating inappropriate prescribing of ICS for respiratory tract infections. ${ }^{20}$ The rate of inappropriate ICS prescribing for the management of symptoms of respiratory infections in subjects without an underlying chronic respiratory condition has not been studied yet in the Netherlands. With data from a national outpatient dispensing database we compared the rate of ICS use without any other respiratory medication in the 12 months before or after a single

\footnotetext{
${ }^{1}$ Scientific Institute for Quality of Healthcare (IQ Healthcare), Radboudumc, Nijmegen, The Netherlands; ${ }^{2}$ Royal Dutch Pharmacists Association (KNMP), The Hague, The Netherlands; ${ }^{3}$ Department of Primary and Community Care, Radboudumc, Nijmegen, The Netherlands and ${ }^{4}$ Department of Clinical Pharmacy, Radboudumc, Nijmegen, The Netherlands.

Correspondence: M Teichert (martina.teichert@radboudumc.nl)

Received 30 March 2014; revised 30 July 2014; accepted 30 August 2014
} 


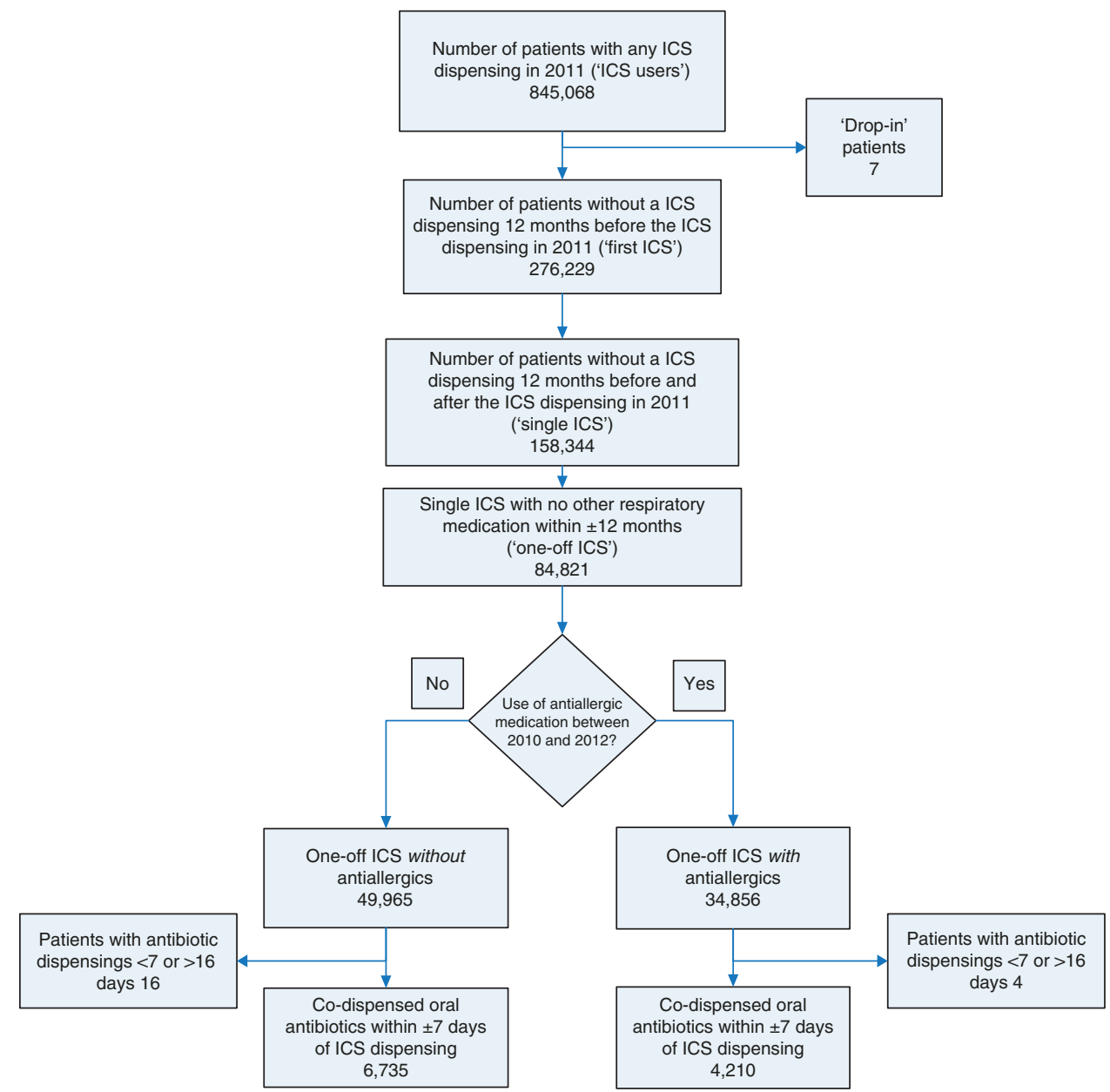

Figure 1. Cohort of one-off inhaled corticosteroids (ICS) users in combination with oral antibiotics (based on data from 1,725 ( $89 \%$ of all) Dutch community pharmacies).

ICS dispensing and in combination with antibiotics in the Netherlands with the results from Australia ${ }^{20}$ and we analysed possible determinants for this.

\section{MATERIALS AND METHODS}

\section{Study design}

We performed a retrospective observational study to evaluate ICS dispensing within routinely collected dispensing data from Dutch community pharmacies.

\section{Data source}

Routinely collected data were extracted from the Dutch Foundation of Pharmaceutical Statistics (SFK). This database has been used before in drug utilisation studies. ${ }^{21,22}$ SFK collects dispensing data from $95 \%$ of the total 1,981 Dutch community pharmacies. ${ }^{23}$ SFK data provide detailed information on the drugs dispensed, including the codes from the ATC system, ${ }^{24}$ the prescribed daily dose and wholesaler's price. Information on patients' sex and year of birth was also available. The data do not contain any information on dispensings from hospital pharmacies or clinical diagnoses. Medication of a specific patient is tracked in the pharmacy over time by a defined unique code per patient. For the degree of urbanisation, the postal code of the dispensing pharmacy was categorised in strata based on the classification of the Dutch Agency of Statistics. ${ }^{25}$ Information on prescribers consisted of an anonymous code per prescriber and information for being a GP or any medical specialist as far as this had been recorded in the pharmacy. The advisory board of SFK approved the study. For this study, data from all Dutch community pharmacies that had provided complete data without changes in patient numbering for the years 2010, 2011 and 2012 could be used.

\section{Measures}

Data were used from pharmacies that had delivered complete data for the whole calendar year from 2010 to 2012. All patients with at least one ICS dispensing during the calendar year 2011, either alone or in single-inhaler combination with long-acting $\beta_{2}$-agonist (LABA; ATC codes: R03BA, R03AK06, R03AK07), were included in the study cohort. The calendar years 2010 and 2012 were used as prior and posterior measurement periods to determine earlier and later dispensings for patients of the cohort. To warrant complete data history for the patients included, patients were excluded who-besides dispensing of a one-off ICS - did not have a dispensing of any other medication in 2011 or 2012 ('drop-in' patients; Figure 1). Within the total group of ICS users, patients who had their first dispensing of an ICS in 2011 without a previous ICS dispensing during the preceding 12 months ('first ICS') were identified. Next, only those patients were selected who had no subsequent dispensing of an ICS in the following 12 months ('single ICS'). Among these patients, those who had not received any other respiratory medication (ATC codes R03, except R03AK06 or R03AK07 or R03BA) in the 12 months prior to or after the single ICS dispensing in 2011 were labelled as 'one-off ICS' users. For these patients co-dispensing of antibiotics was defined as dispensing an oral antibiotic within the drug classes commonly used for respiratory tract infections, comparable to the selection made by Poulos et al. ${ }^{20}$ in their paper (tetracyclines, penicillines, sulphonamides in combination with trimethoprim, quinolones and combinations of these drugs; ATC-codes: J01A, J01C. $J 01 E, J 01 F, J 01 M, J 01 R$ ), within 7 days prior or past of the date of one-off ICS dispensing. As we did not consider information on the diagnosis, we only selected dispensings of these antibiotics for a prescribed period of use 
Table 1. Cohort characteristics of one-off ICS users who were co-dispensed oral antibiotics in $2011^{\text {a }}$

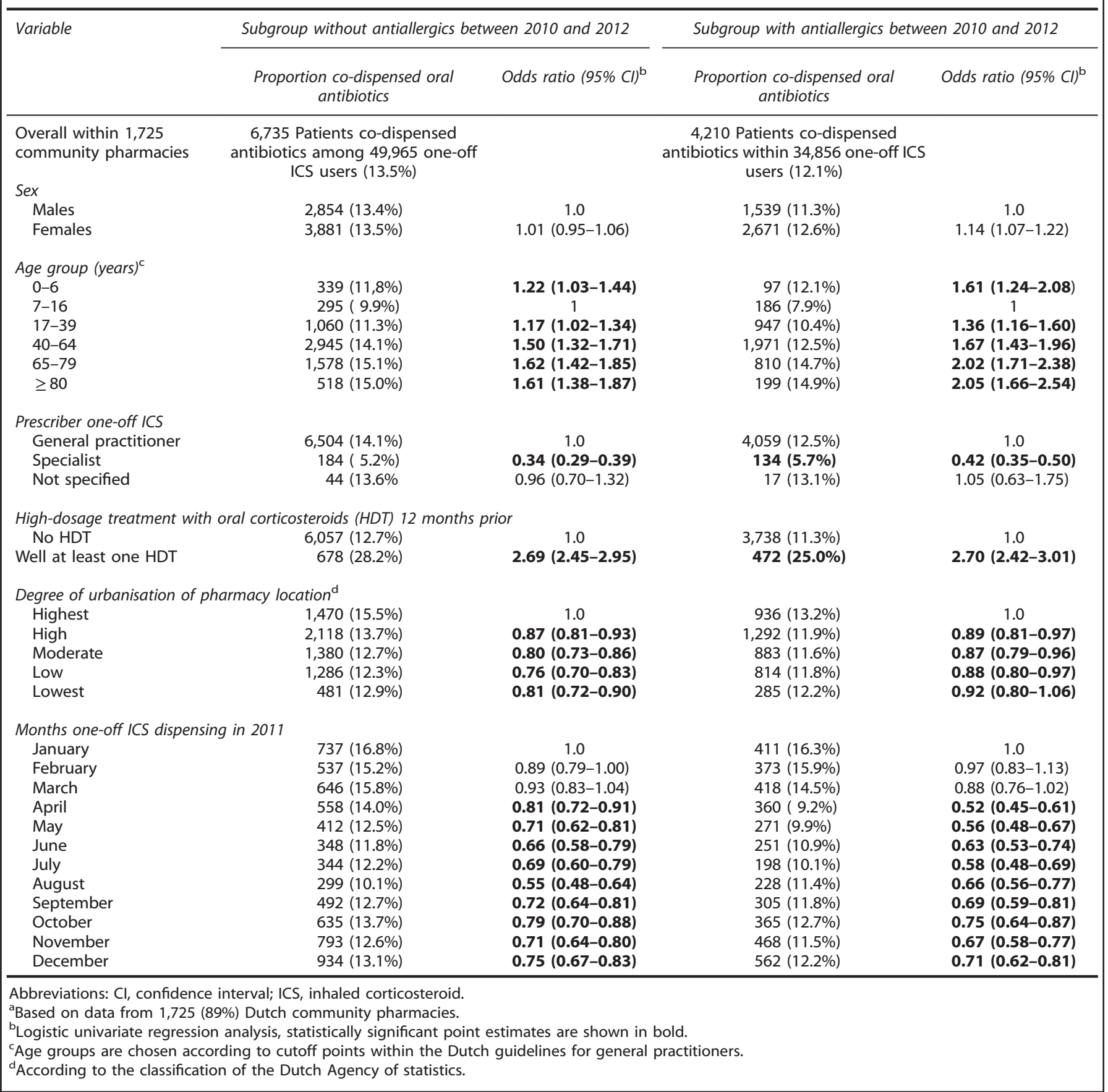

between 7 and 15 days according to the Dutch GP recommendations of antibiotic drug use for respiratory infections. ${ }^{26}$ Patients with a co-dispensed antibiotic for a shorter or longer period of time were not labelled as having 'concomitant antibiotic use'. Usage of a course of high-dose oral corticosteroids was defined as a dispensing with ATC codes H02AB06 or H02AB07 in the 12 months prior to the one-off ICS dispensing. In order to differentiate between subjects with and those without allergies, one-off ICS users with antibiotics were stratified on the basis of having received or not received any dispensing of antiallergic medication (R01AC, R01AD, R03BC, R03DC, R03DX05, R06) between 2010 and 2012.

\section{Data analysis}

For one-off ICS users the proportion of those who were co-dispensed a 7-15-day course of oral antibiotics was calculated, stratified for use of antiallergic medication. These proportions were grouped for the variables sex, age group, type of prescriber of the one-off ICS, earlier oral corticosteroid treatment and the urbanisation degree of the dispensing pharmacy as potential determinants. The relationship of co-dispensing a course of antibiotics in patients with a one-off ICS dispensing was expressed in terms of odds ratios (ORs) using univariate logistic regression for each of the potential confounders. Next, multivariate logistic regression was used to estimate the influence of co-dispensed oral antibiotics on the odds of receiving a one-off ICS dispensing within all users of ICS in 2011. Using forward inclusion we obtained a final model that contained only confounders that changed the OR for antibiotic co-medication by more than $10 \%$. For one-off ICS users with co-dispensed oral antibiotics, the timing of co-dispensing within 7 days before or after the ICS dispensing was analysed. To describe seasonal patterns, the monthly incidence of codispensing was displayed by age group, based on the age categories from 

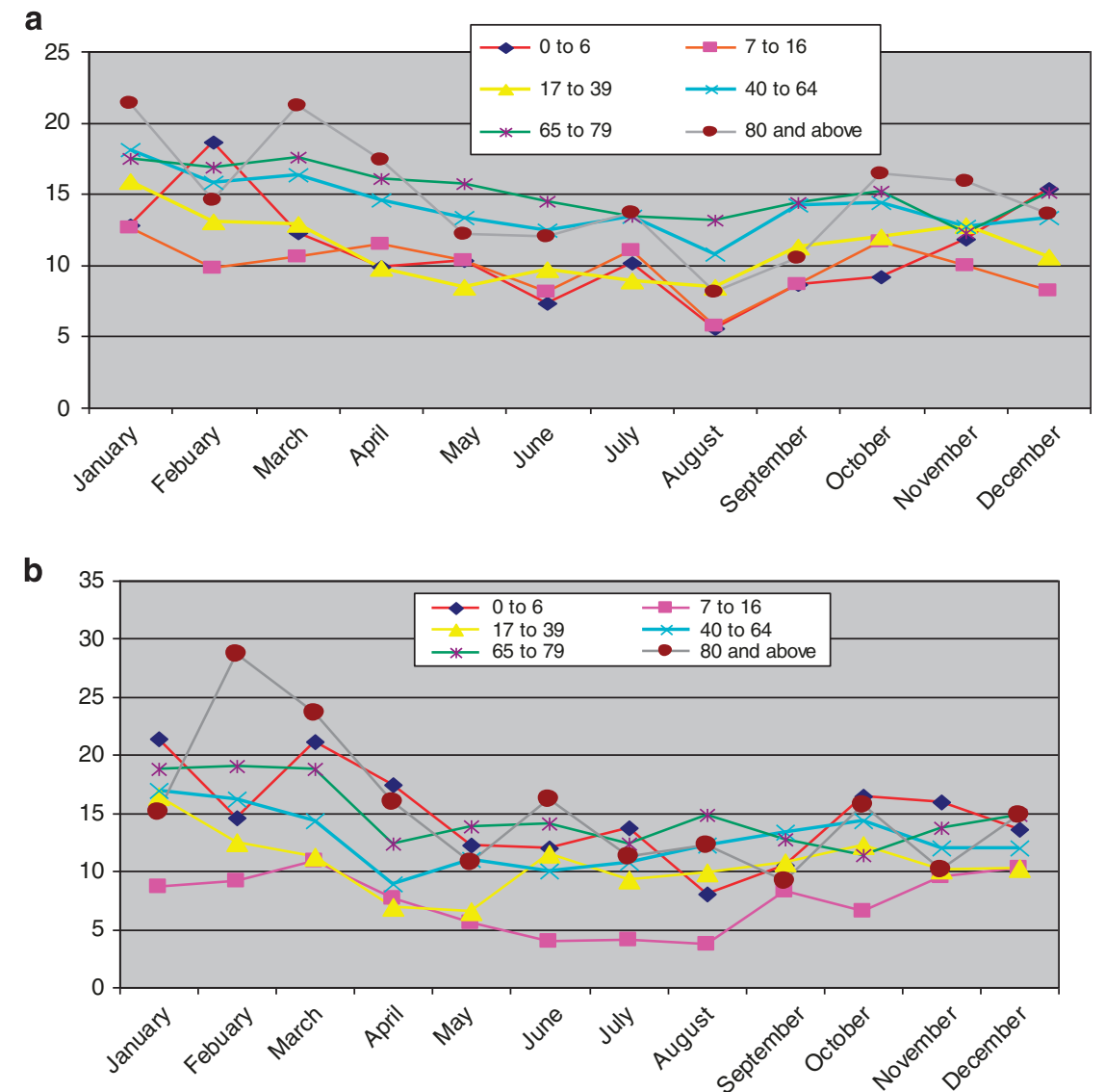

Figure 2. (a) Proportion of individuals with co-dispensing of oral antibiotics within one-off inhaled corticosteroids (ICS) users during 2011 by month for age-categories among patients without antiallergics from 2010 to 2012 (based on data from 1,725 (89\%) Dutch community pharmacies). (b) Proportion of individuals with co-dispensing of oral antibiotics within one-off ICS during 2011 dispensings by month for age-categories among patients with antiallergics from 2010 to 2012.

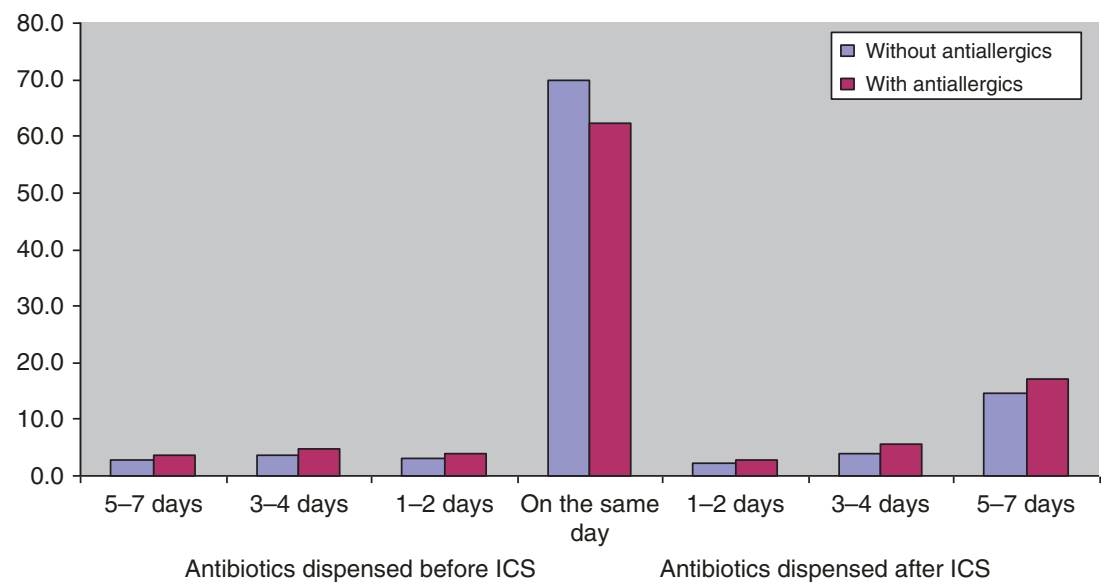

Figure 3. Time lag of co-dispensing of one-off inhaled corticosteroids (ICS) and oral antibiotics in 2011 (based on data from 1,725 (89\%) Dutch community pharmacies).

the Dutch GP guidelines for asthma and COPD. ${ }^{12,13}$ The direct costs of the dispensed one-off ICS medication without the pharmacy dispensing fee were calculated using the official listing prices of the ICS medications in 2011. Total direct costs for one-off ICS medication for the whole country were calculated by extrapolating the information of the number of pharmacies with sufficient data to all Dutch community pharmacies. $P$ values below 0.05 were considered to be statistically significant. Data were analysed with PASW statistics 18.0 (IBM, Chicago, IL, USA).

\section{RESULTS}

Study sample

Data were available from 1,725 (89\%) Dutch community pharmacies. In 2011, these pharmacies had dispensed at least one prescription of an ICS (either alone or in single-inhaler combination with a long-acting betamimetic drug) to 845,068 patients. We identified 84,821 patients $(10.0 \%)$ who had received 


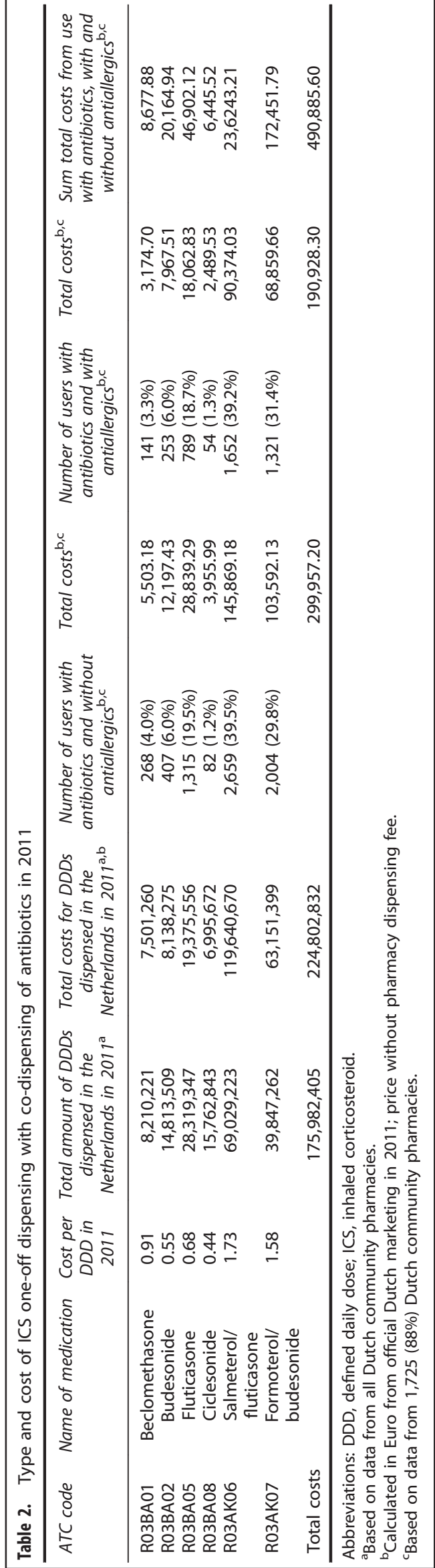

only one ICS prescription and no other respiratory medication during the 12 months before or after this dispensing date ('one-off' ICS, Figure 1). Of the 84,821 one-off ICS users, $59 \%$ were without and $41 \%$ were with earlier use of antiallergic drugs.

Association between antibiotics and one-off ICS dispensing In the univariate logistic regression model, concomitant use of antibiotics increased the odds of receiving a one-off ICS dispensing by nearly five and a half times (OR 5.47, 95\% confidence interval 5.34-5.61). The OR from the multivariate model was lower (OR 4.30, 95\% confidence interval 4.19-4.42) but still substantial.

Patient characteristics within users of one-off ICS with antibiotics In the group of patients with one-off ICS dispensings, 10,945 patients (12.9\% of the one-off ICS users and $1.3 \%$ of all ICS users) were co-dispensed oral antibiotics. Co-dispensing of oral antibiotics among one-off ICS users was slightly higher in the group without antiallergics ( $n=6,735,13.5 \%$ of one-off ICS users) compared with the group with antiallergics ( $n=4,210,12.1 \%$, Table 1). Compared with the age category of $7-16$ years, all other age categories had a significantly higher risk for co-medication of an antibiotic in combination with one-off ICS, which was more than twofold increased in the group of patients aged 65 years or older who were also using antiallergics. One-off ICS in combination with antibiotics was prescribed by GPs in $96.5 \%$ of cases. Earlier high-dose treatment with oral corticosteroids (HDTs) increased the risk for concomitant antibiotics in one-off ICS use in both strata by 2.7 -fold (OR for the combined strata $2.68,95 \%$ confidence interval 2.50-2.88) compared with no earlier HDT use. Furthermore, the combination of one-off ICS and antibiotics was significantly lower in pharmacy regions with a lesser degree of urbanity compared with the highest degree of urbanisation in pharmacy locations, varying between 11 and 24\%. Co-dispensing of antibiotics in one-off ICS users was overall the highest in January and significantly decreased in all months from April to December, varying between 10 and $45 \%$.

Variation of co-dispensed antibiotics in season and age categories Concomitant use of one-off ICS and oral antibiotics occurred throughout the year in all age categories (Figures 2a and b). All patterns showed a slight increase in one-off ICS dispensing with oral antibiotics during the winter months, that was most pronounced for the age category of 80 years and older that also used antiallergics (Figure 2b). Overall, 67\% of co-dispensing of one-off ICS and antibiotics occurred on the same day (Figure 3). The remaining antibiotic co-dispensing was distributed as $23 \%$ during the week after the ICS dispensing and 10\% during the week before. The majority (69.7\%) of one-off ICS dispensings with oral antibiotics were a combination of ICS and LABA (Table 2).

Direct costs of one-off ICS dispensings for respiratory infections The total annual cost for one-off ICS dispensings in combination with antibiotics for the 1,725 pharmacies was $€ 490,885$ annually, equivalent to $€ 550,000$ annually extrapolated to dispensings from all 1,950 Dutch community pharmacies. These costs exclude the dispensing fee, costs for inhalation aids and the costs of the antibiotic itself.

\section{DISCUSSION}

Main findings

In the Netherlands, the percentages for potentially inappropriate management of respiratory infections in patients without chronic airways disease were $13 \%$ of one-off ICS dispensing and $1.3 \%$ of all 
ICS dispensings, considerably lower than previous findings from Australia, reported as $44 \%$ of concomitantly dispensed oral antibiotics among one-off ICS dispensings and $7.3 \%$ of all ICS prescriptions. ${ }^{20}$ Nevertheless, in the Netherlands about half a million Euro of direct costs was involved by this type of inappropriate ICS prescribing. Furthermore, GPs were almost fully responsible for combined prescribing of one-off ICS and oral antibiotics. This may be due to some uncertainty in diagnosing respiratory conditions. Another possibility is that ICS were used for treatment of cough ${ }^{27}$ and a randomised controlled trail concluded that ICS might be effective in reducing cough in non-smoking adults. ${ }^{28}$ However, evidence from a systematic review was inconclusive and ICS use for cough is not advised in current guidelines. ${ }^{29}$ Patients' age, prior HDT use and calendar month of ICS dispensing were variables available in our database that explained some of the one-off ICS dispensing, but there may be other factors relevant that were not covered by our data, such as smoking.

\section{Strengths and limitations of this study}

A strength of our study was that we could use dispensing data from the majority of Dutch community pharmacies. Respiratory medication and antibiotics were fully reimbursed and only available by prescription so that the medication of interest was completely covered by our database. By this, one-off ICS use in combination with antibiotics could be mapped for the whole country, together with related costs. A limitation was that we did not possess information regarding dispensings from hospital pharmacies. However, as hospital pharmacies in the Netherlands only dispense drugs used during hospital stay, this is not likely to bias our results. In order to avoid false positives, we used a quite specific definition for one-off ICS use as only one ICS prescription during 24 months. Thus, our results did not include patients with co-dispensings of oral antibiotics and an allergic disposition who used ICS more than once over 2 years. Consequently, our findings might be too conservative for inappropriate ICS use in respiratory infections. A limitation of our data was that information on diagnoses for antibiotic therapy was not available. Therefore, we only included short-course antibiotic therapy between 7 and 15 days, according to the Dutch GP recommendations of antibiotic drug use for respiratory infections. ${ }^{26}$ The assumption that one-off ICS were used for treatment of respiratory infections was assured by the fact that two-thirds of the co-dispensation of ICS and antibiotics occurred on the same day. Furthermore, concomitant antibiotic use increased the likelihood of one-off ICS prescribing within ICS users by more than 4 times. The estimated costs for one-off ICS dispensings were limited to direct costs by the official listing price of the ICS medication in 2011, which were available in the database used. Other related costs to be considered are pharmacy dispensing fees and costs for training on use of inhalation medication and inhalation aids, but information on these determinants was not covered by our data.

Interpretation of findings in relation to previously published work Our considerably lower findings compared with those from Australia may be partly due to the more specific definition of one-off ICS use in our study with no use of other respiratory medication 12 months before or after, whereas Poulos et al. ${ }^{20}$ used a period of 6 months. However, this difference only accounts for numbers of one-off ICS dispensings within all ICS users and not the percentage of antibiotic co-medication within this group. By our more stringent definition for one-off ICS use, concomitant use of other respiratory medication from earlier dispensings should be excluded and consequently the chance of false-positive labelling for one-off ICS use was diminished. Our findings are not likely to be explained by the shopping behaviour of ICS users, as Dutch patients predominantly visit one community pharmacy ${ }^{30}$ and we additionally excluded drop-in patients as those who received only one dispensing within 2 years. Furthermore, our results are unlikely to be due to poor adherence to ICS, as ICS in asthma as well as COPD guidelines are at least a second step in inhalation treatment, and consequently any other respiratory medication should have been detected within the year before or after the one-off ICS dispensing. ${ }^{12-14}$ Analogous with the results of Poulos et al. ${ }^{20}$ we observed the highest incidences of co-dispensing during the late winter months. This pattern did not differ for earlier use of antiallergic drugs.

Implications for future research, policy and practice

The result that $10 \%$ of ICS users only received one ICS dispensing without any other respiratory medication within the prior and posterior year suggests that potentially inappropriate ICS use might be higher than one-off ICS dispensings in combination with antibiotics, on which our study focussed. Further research is needed to elucidate clinical considerations for ICS prescribing in clinical practice in order to assess and improve the degree of implementation of GP guidelines in primary care.

\section{Conclusions}

The rate of one-off ICS dispensing in combination with oral antibiotics in the Netherlands was 13\% within one-off ICS dispensings, which was considerably lower than the $44 \%$ reported from Australia. Nevertheless, there is room for improvement. About half a million Euro of direct costs could be saved annually by improving this type of inappropriate ICS prescribing.

\section{ACKNOWLEDGEMENTS}

The authors are responsible for the use made of the data in this paper. The advice of Andrea Sellink, AstraZeneca, in preparing the manuscript is appreciated.

\section{CONTRIBUTIONS}

MT, TS, PdS, LvdN and MW conceived the study; MT performed the statistical analysis and drafted the initial version of the manuscript. All authors contributed to the manuscript and have read and approved the final manuscript.

\section{COMPETING INTERESTS}

The authors declare no conflict of interest.

\section{FUNDING}

The authors declare that no funding was received.

\section{REFERENCES}

1 Jones R, Dickson-Spillman M, Mather M, Marks D, Shakell B. Accuracy of diagnostic registers and management of chronic obstructive pulmonary disease: the Devon primary care audit. Respir Res 2008; 9: 62.

2 Adams N, Bestall J, Malouf R, Lasserson T, Jones P. Beclomethasone versus placebo for chronic asthma. Cochrane Database Syst Rev 2007; 2

3 Suissa S, Ernst $P$, Benayouri S, Baltzan M, Cai B. Low-dose inhaled corticosteroids and the prevention of death from asthma. N Engl J Med 2000; 343: 332-336.

4 Sin D, Man J, Shapre H, Gan W, Man S. Pharmacological management to reduce exacerbations in adults with asthma: a systematic review and meta-analysis. JAMA 2004; 292: 367-376.

5 Jen R, Rennard S, Sin D. Effects of inhaled corticosteroids on airway inflammation in chronic obstructive pulmonary disease: a systematic review and meta-analysis. Int J Chron Obstruct Pulmon Dis 2012; 7: 587-595.

6 Gartlehner G, Hansen R, Carson S, Lohr K. Efficacy and safety of inhaled corticosteroids in patients with COPD: a systematic review and meta-analysis of health outcomes. Ann Fam Med 2006; 4: 253-262.

7 Glaab T, Taube C. Effects of inhaled corticosteroids in stable chronic obstructive pulmonary diseaese. Pulm Pharmacol Ther 2011; 24: 15-22. 
8 Calverley P, Stockley R, Seemungal T, Hagan G, Willits L, Riley J et al. Reported pneumonia in patients with COPD: findings from the INSPIRE study. Chest 2011; 139: $505-512$

9 Crim C, Calverley P, Anderson J, Celli B, Ferguson G, Jenkins C et al. Pneumonia risk in COPD patients receiving inhaled corticosteroids alone or in combination: TORCH study results. Eur Respir J 2009; 34: 641-647.

10 GINA (Global strategy for asthma management and prevention). http://www. ginasthma.org/documents/4. 2012; accessed on 29th of July 2014

11 GOLD (Global strategy for the diagnosis, managment and prevention of chronic obstructive pulmonary disease). http://www.goldcopd.org/guidelines-globalstrategy-for-diagnosis-management.html. 2014; accessed on 29th of July 2014.

12 Geijer R, Chavannes N, Muris J, Sachs A, Schermer T, Smeele I et al. NHG standaard Astma bij volwassenen. Huisarts Wet 2007; 50: 537-551.

13 Smeele I, Van Weel C, Van Schayck C, Van der Molen T, Thoonen B, Schermer T et al. NHG standaard COPD. Huisarts Wet 2007; 50: 362-379.

14 Bindels P, Van de Griendt E, Grol M, Van Hensbergen W, Steenkamer T, Uijen J et al. NHG standaard astma bij kinderen. Huisarts Wet 2014; 57: 70-80.

15 NN. NSAID's al jaren meest gebruikt. http://www.sfk.nl/nieuws-publicaties/PW/ 2013/nsaid2019s-al-jaren-meest-gebruikt. 2013; accessed on 12th of March 2014.

16 NN. Uitgaven top 10 sterk gewijzigd. http://www.sfk.nl/nieuws-publicaties/PW/ 2013/Uitgaven_top_10. 2013; accessed on 12th of March 2014.

17 Lucas A, Smeenk F, Smeele I, Van Schayck C. Overtreatment with inhaled corticosteroids and diagnostic problems in primary care patients, an exploratory study. Fam Pract 2008; 25: 86-91.

18 White P, Thornton H, Pinnock H, Georgopoulos S, Booth H. Overtreatment of COPD with inhaled corticosteroids-implications for safety and costs: crosssectional observational study. PLoS One 2013; 8: 75221.

19 De Miguel-Diez J, Carrasco-Garrido P, Rejas-Tuierrez J, Martin-Centeno A

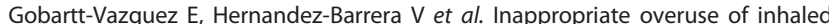
corticosteroids for COPD patients: impact on health costs and health status. Lung 2011; 189: 199-206.

20 Poulos L, Ampon R, Marks G, Reddel H. Inappropriate prescribing of inhaled corticosteroids: are they being prescribed for respiratory tract infections? A retrospective cohort study. Prim Care Respir J 2013; 22: 201-208.

21 Teichert M, Visser LE, Dufour M, Rodenburg E, Straus SMJM, De Smet PAGM et al. Isotretinoin use and compliance with the Dutch Pregnancy Prevention
Programme: a retrospective cohort study in females of reproductive age using pharmacy dispensing data. Drug Saf 2010; 33: 315-326.

22 Ruiter R, Teichert M, Straus S, Stricker B, Visser L. Concomitant use of contraceptives and potentially teratogenic medicinal product: results from a study using pharmacy dispensing data in the Netherlands. Reprod Sci 2012; 19: 987-994.

23 Dutch Foundation of Pharmaceutical Statistics S. Data en feiten. http://www.sfk. $\mathrm{nl} /$ pdf-documenten/data-en-feiten/SFKDataenfeiten2013.pdf. 2012; accessed on 12th of March 2014

24 World Health Organization Collaborating Centre for Drug Statistics Methodology. Guidelines for ATC Classification and DDD Assignment. Oslo, 2004.

25 Centraal Bureau van de Statistiek C. Stedelijkheids klassen http://www.cbs.nl/nl$\mathrm{NL} /$ menu/methoden/begrippen/default.htm?ConceptID=658. 2014; accessed on 12 of March 2014

26 Verheij $T$, Hopstaken $R$, Prins J, Salomé $P$, Bindels $P$, Ponsioen B et al. NHG-Standaard Acuut hoesten (Eerste herziening). Huisarts Wet 2011; 54: 68-92.

27 Gibson PG, Chang AB, Glasgow NJ, Holmes PW, Katelaris P, Kemp AS. CICADA: Cough in Children and Adults: diagnosis and assessment. Australian cough guidelines summary statement. Med J Aust 2010; 192: 265-271.

28 Ponsioen B, Hop W, Vermue N, Dekhuizen P, Bohnen A. Efficacy of fluticasone on cough: a randomised controlled trial. Eur Respir J 2005; 25: 147-152.

29 El-Gohary M, Hay A, Coventry P, Moore M, Stuart B, Little P. Corticosteroids for acute and subacute cough following respiratory tract infection: a systematic review. Fam Pract 2013; 30: 492-500.

30 Buurma $H$, Bouvy ML, PAGM De Smet, Floor-Schreudering A, Leufkens HGM, Egberts ACG. Prevalence and determinants of pharmacy shopping behaviour. J Clin Pharm Therap 2008; 33: 17-23.

(c) (1) (2) This work is licensed under a Creative Commons AttributionNonCommercial-ShareAlike 4.0 International License. The images or other third party material in this article are included in the article's Creative Commons license, unless indicated otherwise in the credit line; if the material is not included under the Creative Commons license, users will need to obtain permission from the license holder to reproduce the material. To view a copy of this license, visit http:// creativecommons.org/licenses/by-nc-sa/4.0/ 